\title{
UNDERSTANDING COGNITIVE PROCESS OF SIGHTED PEOPLE IN READING TACTILE PICTOGRAM BY TOUCH
}

\author{
Fariz Fadhlillah
}

Accepted December. o3, 2020; Approved June. 11, 2021.

\begin{abstract}
The tactile pictogram is designed as an orientation and mobility system for the visually impaired in the train station. How to access the information through touch. However, this design is also intended to be used by the sighted person. To make this design becomes universal, in the designing process, it is necessary to consider the cognitive processes that occur when the sighted people read a tactile pictogram as an input for data comparisons. Data collection methods are divided into three, namely surveys to obtain primary data, action research to obtain secondary data, and document study to obtain tertiary data. The study was conducted by testing the pictogram media that had been previously designed with a semiotic approach to the ancient visual language theory of Primadi Tabrani. The data results were analyzed quantitatively and qualitatively. At the analysis process, findings are hoped to be able to reveal definitional statements about the cognitive ability that is used by sighted people in reading tactile pictograms, namely imagery or memory.
\end{abstract}

Keywords: cognitive process; neural mechanism; sighted; reading by touch; tactile pictogram; universal

\section{Introduction}

The number of visually impaired and the problems it causes are increasing every year. Those can be seen from WHO data in 2010 the number of visually reaches up to 285 million and sets to triple by 2050. Thus, this phenomenon demands an inclusive public space to grow massively from now on. Mainly in the public transportation sector, especially train stations, it is an ideal facility that can increase the daily mobility of the visually impaired in the city. Personally, the researcher recommends train stations research \& development team update the symbol sign so that the visually impaired can also access it. So, it is hoped that no one is limited in access- ing information about how to use the facilities owned by the station.

Responding to these opportunities, a universal tactile pictogram as an orientation and mobility system for the visually impaired at train stations is personally developed. The main strategy is designing pictograms based on the visually impaired ability and habit in reading visual information on tactile media. In addition, in the design process, it needs to consider the perceptual process of the sighted when they access and understand the data represented as symbols on the pictogram media. The goal is to easily understand the intersection of how visually impaired and sighted understand sym- 
bols with the same meaning through their respective ways of access. Consequently, the trial study needs to be carried out on the sighted with the same mechanism as for the visually impaired. Apart from being important to produce an optimal design, on the other hand, this process has benefits. The benefit is that the study can automatically become a research process reference for other designers in designing graphic symbols for the visually impaired.

Overall, the study is to test the pictogram media that had been designed in a paper entitled Building General Perception for Blind People as Orientation System in The Bandung City Train Station through The Pictogram Design (Fariz, 2018). The pictogram design uses semiotic approach in adapting Primadi Tabrani's ancient visual language theory. The reason for choosing this theory is because it has the advantage of multiple images which are described as the motion of objects. So, conceptually it is expected that the visually impaired people can identify shapes, read the motion, and understand its contextual meaning. The trial results revealed that the visually impaired only able to identify objects. Specifically, it was only for those who had received verbal intervention to recognize graphic objects with mnemonic techniques. Meanwhile, the motion and contextual meaning cannot be read. It is concluded that the visually impaired use their memory capabilities in reading the tactile pictogram design.

The data collected is divided into three types, namely primary data, secondary data, and tertiary data. Data were analyzed quantitatively and qualitatively to get inductive conclusions. The conclusions are expected to answer research questions related to what cognitive ability is used by sighted people when reading tactile pictograms by touch whether it is imagery or memory. The probability of the two cog- nitive abilities refers to the theory in several reference books which states that the basic human cognitive ability in translating representative information through vision will refer to imagery and memory, both processed separately and interconnected. In the end, the finding is used as input data and fundamental to improve the tactile pictogram design concept and system in the next study.

\section{Methodology}

There were three steps carried out hierarchically in collecting data. First, primary data obtained by surveys. Surveys were conducted on 49 sighted people simultaneously in one room. Respondents consisted of 23 men and 26 women with a range of 18-23 years. At first, respondents were encouraged to not communicate with other respondents until the testing process is completed. Then, respondents were directed to read the media with closed eyes and answered questions on a paper questionnaire that was distributed. The time to read was one minute or 60 seconds. The questions are: dia?

1. Can you read the image on the me-

2. What kind of image can you read?

3 . How can you guess the image?

The three questions are classified into two types, namely the main question and the trigger question. The main question is the third question, while the trigger questions are the first and second questions. This classification is made based on the usefulness of the data. The answers generated through the main questions will be used as input data for the qualitative analysis process, while for the trigger questions, the data will be used as data assets. When answering questions, respondents 
were able to not answer if they were unable to guess the image.

Second, secondary data obtained through action research methods. Action research is a method that makes the researcher as respondents too. Technically, trials with this method follow exactly survey steps. Besides being intended to enrich the data during the final analysis process, the selection of this method also has a special purpose to increase knowledge and experience of the researcher in understanding perceptual concept of blindness. This method is considered important by the researcher for anyone who is designing inclusive or universal technology. Because the method emphasizes the tendency in understanding user problems from the user's perspective. On the other hand, the urgency of using this method is based on the background that until now there has not been found an amenable definition of blindness from sighted person.

Third, tertiary data obtained through document study on theories related to the cognitive science both of sighted and visually impaired people in reading graphics representative. The document is books. Broadly speaking, the books are themed on neuroscience, somatosensory code, and visual impairment. The theories are set as the basis for examining the data and problems in research.

The data analysis process is divided into two consecutive stages, namely quantitative and qualitative. Quantitative analysis is carried out only at the end of the surveys to generate conclusions from the primary data by classifying the data variable equations. The variable with the most amount of data is translated as input data for qualitative analysis. Then, the qualitative analysis itself is carried out by comparing and inducing findings from each data to find definitional statements. The expected definitional statements include three things, namely:

1. Cognitive ability that is used by sighted people in reading tactile pictogram by touch.

2. Mechanism hierarchy of sighted people to read symbolized images on pictogram media.

3. Cognitive abilities comparison between the sighted and visually impaired people in reading tactile pictogram by touch.

\section{Theory}

\section{Primadi Tabrani's Ancient Visual Language}

The theoretical description presented in this section is taken from previous papers that have been written by the researcher with the title Building General Perception for Blind People as Orientation System in The Bandung City Train Station through The Pictogram Design (Fariz, 2018) and Seminal Breakthrough in Tactile Pictogram Design for Visually Impaired in Train Station (Fariz, 2020). Ancient visual language is a drawing system that has proximity to Albert Einstein's relativity theory which reveals that space cannot be separated from time. This image system is called Space-Time-Plane (STP) whose characteristics are described in various directions, various distances, and various times. There are three components in learning how to draw with an STP system. These components are image way, inner grammar, and outer grammar. Image way is the way in which objects are drawn. How to arrange various image way in a scene so that you can tell a story is called the inner grammar. Whereas the method of distinguishing image way and the arrangement of expressions between 
panel and one another until the sequence of the panel are able to tell a story is called outer grammar.

\section{Action Research Method}

Action research theory refers to the book Design Science Research: A Method for Science and Technology Advancement (2015). Action research is a method that aims to solve or explain problems in a given system. The nature of action research is exploratory, descriptive, and explanatory. Action research emphasizes observers who have an active role in the investigation process. Researchers have two roles when using this method, namely he may be a participant and at the same time he may wish to evaluate.

\section{Cognitive Science Comparison of Sighted and Visually Impaired in Reading by Touch}

The theory used refers to three books, namely Pain and Touch (1996), Reading by Touch (2003), Sensory Perception (2012). To make writing more efficient, the theoretical review is presented in a table format as follows.

Table 1. Theories Review

Source: Self Courtesy

\begin{tabular}{|l|c|c|c|}
\hline & Sensory System & Cognitive Ability & Neural Mechanism \\
\hline Sighted & Vision & Imagery & Global to Local \\
\hline $\begin{array}{l}\text { Vimally } \\
\text { Impaired }\end{array}$ & Touch & Memory & Local to Global \\
\hline
\end{tabular}

\section{Result}

\section{Prototype Flashback}

The prototype is made of $260 \mathrm{gr}$ paper through the embossing technique. It has
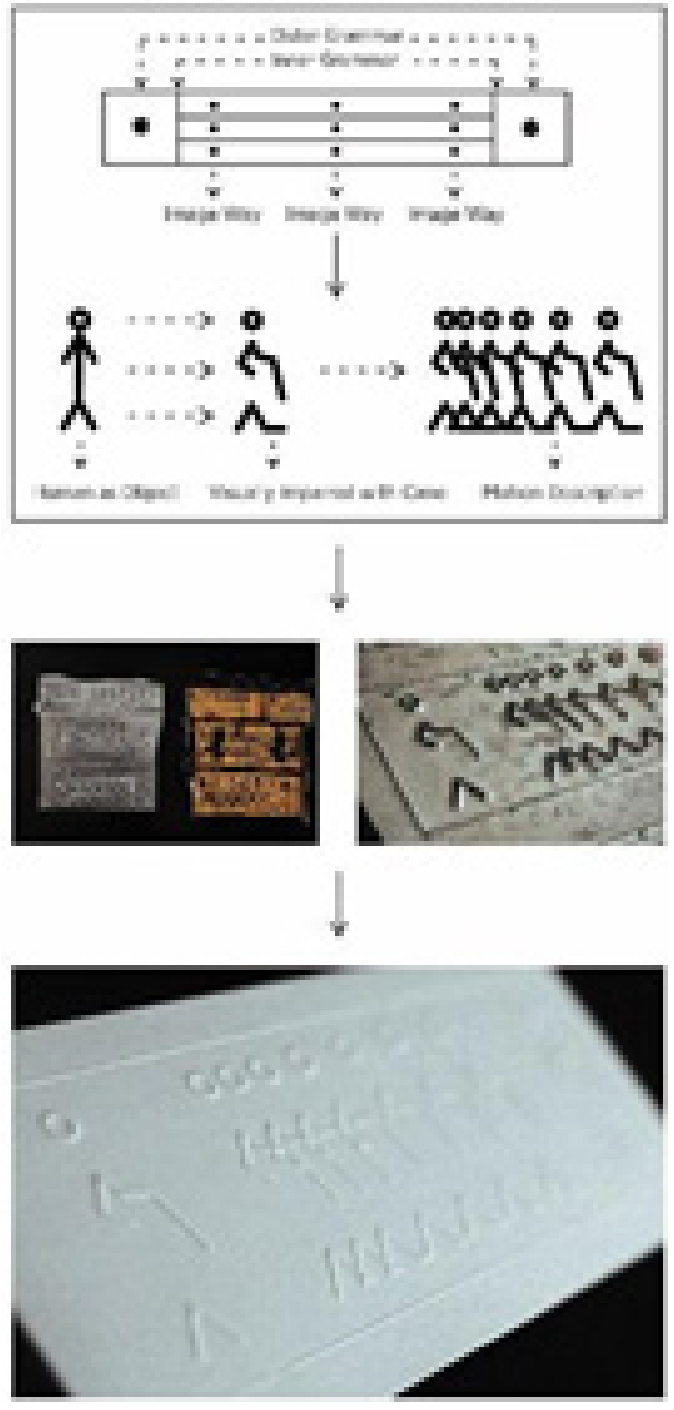

Figure 1. Previous Prototype Design Source: Self Courtesy

a dimension of $10 \mathrm{~cm} \times 5 \mathrm{~cm}$ with a tactile height of $0.48 \mathrm{~mm}$. At first, the prototype is designed by choosing the symbolized object. The consideration in choosing the shape is the object that is most easily recognizable or familiar to the visually impaired then the result is human form idea is chosen. How to draw a human pictogram was then adapted using the drawing system from Primadi Tabrani's ancient visual language theory. The pic- 
togram is thoroughly drawn with a cane being held. The drawing style resembles "stickman" and the motion context is drawn by multiple images. The final tactile pictogram design means "visually impaired is walking". After the visualization process is complete, then the emboss plate is made to produce prototypes.

\section{Surveys}

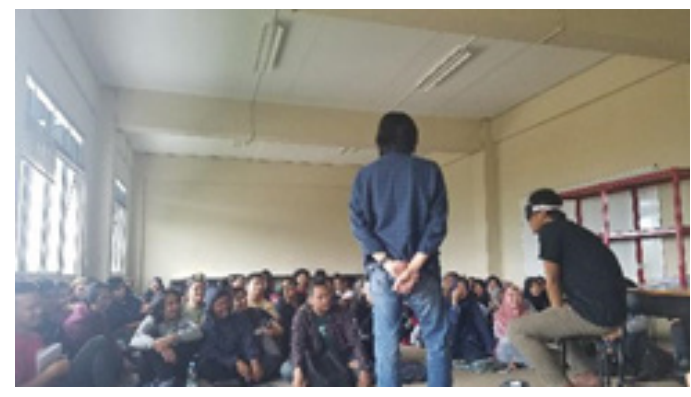

Figure 2. Surveys Process Document Source: Self Courtesy

The trial process is divided into three stages, namely instruction, trial process, and data accumulation. First, instruction is the stage of directing the respondents to read the images on the pictogram media with closed eyes and using their bare hands without tools aid or communication for 60 seconds. Each respondent wore a blindfold. Second, trial process is the reading stage for respondents and after that, the pictogram media are collected before the respondents open the blindfold. Finally, data accumulation is the stage of collecting questionnaire papers containing answers from each respondent. After the questionnaire answers are collected, respondents are allowed to open their eyes and see the pictogram media that has been read.

The trial results reveal findings with contrasting data. For the first question, answers were collected revealed finding that each respondent was able to read the

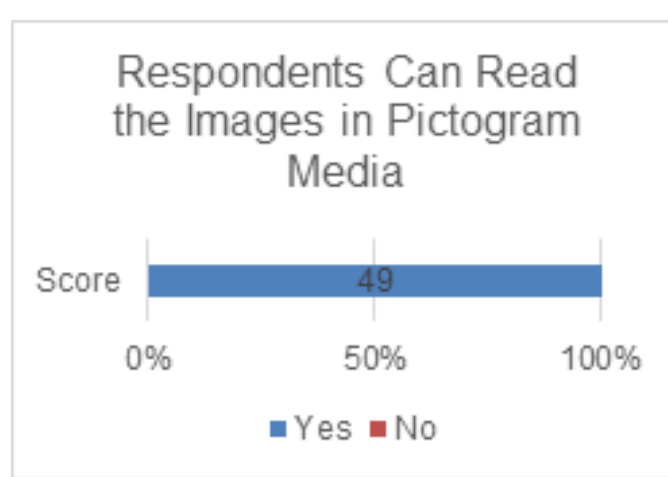

Figure 3. Graphic Data I Source: Self Courtesy

presence of an icon on the media through the tactile height they touched. It means the tactile height pictogram using international standard tactile height in braille is also accessible for the sighted. So, this measurement reliably becomes the minimum measurement standard for designing hand-accessible tactile graphics.

\section{Respondents Accuracy in Guessing Objects in Pictogram Media}

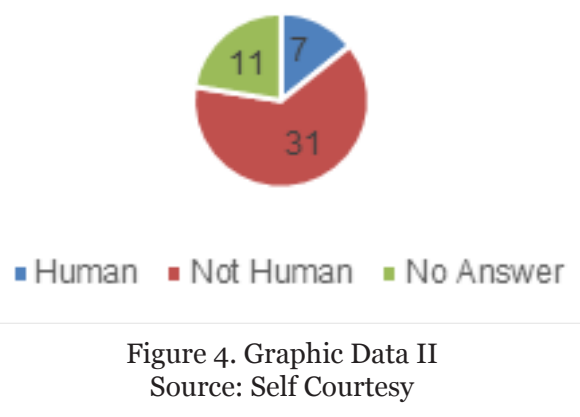

However, even though it has been revealed that sighted people also have a high-sensitivity sense of touch, but the accuracy is not directly proportional. This can be seen in the answers to question number two, it can be concluded that respondents are unable to guess the object on the pictogram media precisely. In more detail, 31 people guessed the pic- 
togram with not human objects, 7 people guessed it right, and 11 people didn't give an answer or could only feel the difference in texture. To some extend, some respondents gave reasons for not answering because the pictogram and media sizes were not large enough. Furthermore, the data inputted to answer question number three came from 38 respondents.

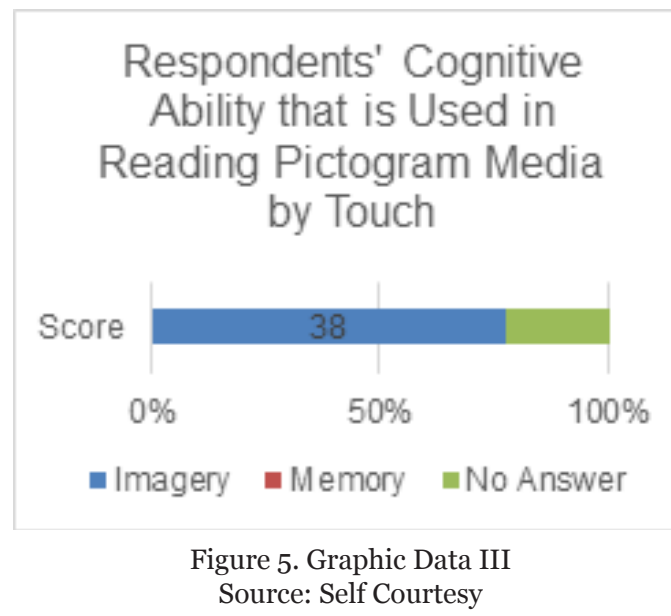

Question number three succeeded in opening a deeper causative factor analysis related to the respondents' background in answering question number two. It starts with a conclusion to answer question number three which reveals that sighted people use their imagery ability when reading tactile pictograms by touch regardless they are right or wrong in guessing object. Overall, the reading mechanism is the same, namely, it is starting from identifying particular geometric of shape as a whole and then connecting the analysis results to guess the holistic symbolized shape. Specifically, the detail shape identification is done by dissecting the tactile elements. After doing a holistic analysis and before guessing, respondents use memory to cross-check whether their mental guess is right or wrong.

For those who guess the pictogram shape was human, respondents had strong visual queries about human body anatomy and how to describe it into a $2 \mathrm{D}$ form. It also shows respondents had and used memory well during the test process. On the other hand, respondents who were false in guessing the symbolized shape are found to be interesting cases. Although they did the same reading mechanism, the reason why they answered incorrectly was that they ignored and or did not recognize the objects imagery as a whole. So, they guess on the partially recognized shapes.

\section{Action Research}

Trials using action research method produced identical data such as data from surveys. During the trials, the researcher simulated himself as a person who did not know the previous tactile pictogram design before and a visually impaired. The reading process begins with identifying every detail of pictogram shape with one finger following the tactile height. At this stage, the researcher focuses on the question in the head about "what this is" and "what the relationship between this form and other forms is". Mental images related to form imagery are built up during this process. After the form imagery arrangement is complete, then visual memory appears that matches the shape. The visual memories that appear are various, such as the anatomy of the human body in a realist, cartoon, stickman, or illustrative style as much as the researchers' eyes experience seeing those shapes.

\section{Discussion}

Surveys, action research, and theories reveal identical findings. For the sighted, it can be underlined that imagery is a very reliable ability to read representative im- 
ages for example tactile pictograms either by vision or touch. The better people use the imagery, the better they built memory or cognitive analysis output and vice versa.

\section{Conclusion}

From the studies that have been conducted, it can be concluded that the sighted and the visually impaired use both imagery and memory as well when reading tactile pictogram by touch. However, the process of using it is reversed. Visually impaired people tend to use memory, while sighted people use imagery. In addition to these differences, there is also an identical reading mechanism equation, namely that both of them start to understand the meaning of the pictogram as a whole by identifying the particular geometric of shape from local to global. So, a familiar shape, easy to categorize by touch, and high-accessible hardware (such as scale, tactile height, and material) are three mandatory criteria that must be met to make the tactile pictogram design reach universal. The universal context specifically refers to the definition of a tactile pictogram drawing system that is generated based on an understanding of the neural mechanism equations in the somatosensory cortex of sighted and visually impaired people when reading representative tactile graphic.

\section{References}

Barth, FG. Giampieri-Deutsch, Patrizia. \& Klein, HD (eds.). (2012). Sensory Perception. Wien: Springer.

Dresch, A. Lacerdo, P.D. \& Antenus, J.A.V. (2015). Design Science Research. Cham: Springer

Fadhlillah, F. "Building General Percep- tion for Blind People as Orientation System in The Bandung City Train Station through The Pictogram Design", in 1st International Conference on Art for Technology, Science, and Humanities (ARTESH) ITB, Bandung, 2018.

Fadhlillah, F. (2020). SEMINAL BREAKTHROUGH IN TACTILE PICTOGRAM DESIGN FOR VISUALLY IMPAIRED IN TRAIN STATION. Ultimart: Jurnal Komunikasi Visual, 13(2), 55-6o. https://doi.org/https:// doi.org/10.31937/ultimart.v13i2.1841

Friedmann, M. Carterette, E. (1996). Pain and Touch. USA: Academic Press

Millar, S. (2003). Reading by Touch. New York: Routledge

Tabrani, P. (2012) Bahasa Rupa, ed. 2, Bandung: Kelir.

who.int [Internet]. Bandung: World Health Organization; Year [2018 Jun 1]. Available from: https://www.who. int/pbd/en/

who.int [Internet]. Bandung: World Health Organization; Year [2018 Jun 1]. Available from:https:// www.who.int/news-room/factsheets/detail/blindness-and-visual-impairment\#: : text $=$ Mild\%20 \%E2\%80\%93\%2opresenting\%20visual\%20acuity\%20worse, acuity\%20 worse $\% 20$ than $\% 203 \% 2 \mathrm{~F} 60$ 